INTERNATIONAL JOURNAL OF ENGINEERING, SCIENCE AND TECHNOLOGY

www.ijest-ng.com

(C) 2010 Multi Craft Limited. All rights reserved

\title{
Thermal stability of nano structured fly ash synthesized by high energy ball milling
}

\author{
J. Babu Rao ${ }^{*}$, P. Narayanaswami ${ }^{2}$ and K. Siva Prasad ${ }^{3}$ \\ ${ }^{1,2}$ A U College of Engineering, Andhra University, Visakhapatnam, A.P, INDIA - 530003 \\ ${ }^{3}$ National Institute of Technology, Trichy, Tamil Nadu, INDIA - 620015 \\ "Corresponding Author: e-mail: baburaojinugu@yahoo.com
}

\begin{abstract}
In this paper, an attempt has been made to modify the micro sized fly ash into nano structured fly ash using High Energy Ball Mill. The smooth, glassy and an inert surface of the fly ash can be altered to a rough and more reactive state by this technique. Ball milling was carried out for the total duration of 30 hours. The sample was taken out after every 5 hours of milling for characterizing. The nano structured fly ash was characterized for its crystallite size, lattice strain and percentage of crystallinity by using X-Ray Diffractometer. It was found that for the $30 \mathrm{hrs}$ milling, the crystallite size was reduced from $92 \mathrm{~nm}$ to $29 \mathrm{~nm}$ and the percentage of crystallinity got reduced from $63 \%$ to $38 \%$. The size, shape and texture of the fresh as well as nano structured fly ash were studied using Scanning Electron Microscopy (SEM). The fresh fly ash particles are mostly spherical in shape. The shape of the $30 \mathrm{~h}$ milled particles is irregular and the surface morphology is rough. Isothermal annealing was carried out on $30 \mathrm{~h}$ ball milled fly ash from 100 to $800{ }^{\circ} \mathrm{C}$ for various times. The initial grain size of $29 \mathrm{~nm}$ for as-milled sample increased to $30.9 \mathrm{~nm}$ and 31.7 $\mathrm{nm}$ after annealing for $8 \mathrm{~h}$ at 100 and $200{ }^{\circ} \mathrm{C}$ respectively. Whereas this trend was slightly higher for higher temperatures, this increase was in the order of $29 \mathrm{~nm}$ to $33.43 \mathrm{~nm}, 35.35 \mathrm{~nm}, 36.53 \mathrm{~nm}, 37.78 \mathrm{~nm}, 40.42 \mathrm{~nm}, 41.93 \mathrm{~nm}$ after annealing for $4 \mathrm{~h}$ at 300 , 400, 500, 600, 700 and $800{ }^{\circ} \mathrm{C}$ respectively. Hence, small crystallite size enhancement with good amount of residual strain recovery was observed during the isothermal annealing.
\end{abstract}

Keywords: Nano materials, Particulates and Powders, XRD- analysis; Fly ash.

\section{Introduction}

Nanoscience and nanotechnology has become the buzz-word in recent years. It has appeal of miniaturization: also it imparts enhanced electronic, magnetic, optical and chemical properties to a level that cannot be achieved by conventional materials (Bhushan, 2004; Kohar, 2004). A variety of ways have been reported to synthesize nano level materials such as plasma arcing, chemical vapor deposition, electro deposition, sol-gel synthesis, high intensity ball milling etc (Cao, 2004). Among these methods high energy milling has advantages of being simple, relatively inexpensive to produce, applicable to any class of materials and can be easily scaled up to large quantities (Baraton, 2003). In this mechanical treatment, powder particles are subjected to a severe plastic deformation due to the repetitive compressive loads arising from the impacts between the balls and the powder. This produces novel crystalline and amorphous materials with crystallite sizes at the nanometer scale (Carl, 2006).

Metal matrix composites are advanced materials resulting from a combination of two or more materials in which tailored properties are realized. It is well known that the particle- reinforced metal matrix composites have excellent mechanical properties due to the addition of the high strength and high modulus particles like $\mathrm{TiC}, \mathrm{Al}_{2} \mathrm{O}_{3}, \mathrm{SiC}, \mathrm{TiB}_{2}$ etc. However the ductility of the MMCs deteriorates with high ceramic particle concentration (Akio et al., 1999). It is of interest to use nano sized ceramic particles to strengthen the metal matrix, so called metal matrix nano composites (MMNC) while marinating good ductility (Akio et al., 1999; Mussert, 2002). Currently, there are several fabrication methods of MMNCs, including mechanical alloying with high energy milling (Chen et al., 1997), ball milling (Utriga et al., 2003), nano sintering (Groza, 1999) vortex method (Akio et al., 1999), spray deposition, electrical plating, sol - gel synthesis, laser deposition etc. 
Casting, as a liquid phase process, is capable of producing products with complex shapes. It will be attractive to produce as-cast lightweight bulk components of MMNCs with uniform reinforcement distribution and structural integrity. Habibnejad-Korayem et al. (2009) reported the enhanced properties of $\mathrm{Mg}$ based composites reinforced with $\mathrm{Al}_{2} \mathrm{O}_{3}$ nano particles by vortex method. A. Mazahery et al. (2009) developed the high performance A356 - nano $\mathrm{Al}_{2} \mathrm{O}_{3}$ composites by vortex method. Yar et al. (2009) studied the microstructure and mechanical properties of aluminium alloy matrix composite reinforced with nano particle $\mathrm{MgO}$ by vortex method. Habibnejad-Korayem et al. (2009) carried out the study on tribological behaviour of pure Mg and AZ31 magnesium alloy strengthened with $\mathrm{Al}_{2} \mathrm{O}_{3}$ nano particles by vortex method. Yang et al. (2004) studied the effect of nano sized SiC particles reinforced in molten aluminium alloy by ultrasonic dispersion. Lan et al. (2004) reported the studies on microstructure and microhardness of $\mathrm{SiC}$ nano particles reinforced magnesium composites fabricated by ultrasonic method.

In all the above considerations, vortex method of Aluminium based MMNCs fabrication of the nano reinforcements was added to the melt at a temperature range of $800-850{ }^{\circ} \mathrm{C}$ for the period of 30-45 minutes. Prior to addition of these nano particles, it has to be preheated for the period of $2-3$ hours at a temperature range of $700-800{ }^{\circ} \mathrm{C}$. The grain growth and phase transformations will change the useful properties of nanostructured materials. Therefore, one fundamental requirement is that the nano sized grains and consequently the excellent properties should be retained for a desired period of time and within a significant temperature range. The grain growth of nano structured materials has been the subject of many studies in recent years (Shaw et al., 2003; Boylan et al., 1991). Zhou et al. (2001) investigated the grain growth in the nanostructured aluminium with an initial grain size of $26 \mathrm{~nm}$. De-Castro and Mitchell (2005) investigated the grain growth in nano crystalline aluminium with initial grain sizes of $22 \mathrm{~nm}$ and 40 nm produced by mechanical attrition using stainless steel and nylon media respectively. No much work was available on this aspect i.e. studies on thermal stability of nano structured reinforced materials during the fabrication of MMNCs by vortex method. Hence it is worthy to carry out the some studies on thermal stability of nano structured materials to be used as reinforcements for the fabrication of MMNCs by vortex method.

There has been an increasing interest in composites containing low density and low cost reinforcements. Among the various reinforcements used, fly ash is one of the most inexpensive and low density reinforcements available in large quantities as solid waste by product from combustion of coal in thermal power plants (Kumar et al., 2009; Sudarshan, 2008; Ramachandra and Radhakrishna, 2007; Mondal et al., 2009; Daoud et al., 2009; Uju and Oguocha, 2009). Fly ash particles are classified into two types, precipitator and cenosphere. Generally, the solid spherical particles of fly ash are called precipitator fly ash and the hollow particles of fly ash with density less than $1.0 \mathrm{~g} / \mathrm{cm}^{3}$ are called cenosphere fly ash. One common type of fly ash is generally composed of the crystalline compounds such as quartz, mullite and hematite, glassy compounds such as silica glass, and other oxides. The precipitator fly ash, which has a density in the range of $2.0-2.5 \mathrm{~g} / \mathrm{cm}^{3}$ can improve various properties of selected matrix materials, including stiffness, strength and wear resistance and reduce the density. Cenosphere fly ash, which consists of hollow fly ash particles, can be used for the synthesis of ultra light composite materials due to its significantly low density, whch is in the range of 0.4-0.7 g/ $\mathrm{cm}^{3}$, compared with the densities of metal matrices, which is in the range of 1.6-11.0 g/ $\mathrm{cm}^{3}$ (Kumar et al., 2007; Matsunaga et al., 2002).

In this paper an attempt has been made to modify the fly ash by transforming the micro sized fly ash into nano structured fly ash using high energy ball mill. The smooth, glassy and an inert surface of the fly ash can be altered to a rough and more reactive state by this technique. And also some studies are carried out to assess the thermal stability of ball milled nano structured fly ash which is to be used as reinforcements for the fabrication of MMNCs by vortex method.

\section{Experimental Procedure}

\subsection{Sample preparation}

Fly Ash particles used for this study were procured from Thermal power plant of RINL (Rashtriya Ispat Nigam Limited), Visakhapatnam Steel Plant, Visakhapatnam, India. The composition of the received fly ash samples were given in Table 1. A 500 grams weight of fly ash sample was taken in a graphite crucible and allowed to preheat in the muffle furnace at $800^{\circ} \mathrm{C}$ for 3 hours to find out the loss on ignition and it was found to be $2.4 \%$. Preheated fly ash after cooling to room temperature was washed in distilled water and removed the carbon that creamed up during washing. It was then dried at $110^{\circ} \mathrm{C}$ for 48 hours to get rid of water. Dried fly ash has been sieved for 15 minutes using BSS meshes ranging in size from 100 to 350 by Rotap Sieve shaker. Figure 1 shows the mesh size and weight fraction distribution of fly ash powder after 15 minutes sieving. The results show that more than $70 \%$ by weight retained in $-200+350$ mesh; hence this size was chosen as input material for ball milling.

Table 1. Chemical composition of as-received fly ash, wt. \%

\begin{tabular}{|c|c|c|c|c|c|c|c|c|}
\hline $\mathrm{SiO}_{2}$ & $\mathrm{Al}_{2} \mathrm{O}_{3}$ & $\mathrm{Fe}_{2} \mathrm{O}_{3}$ & $\mathrm{TiO}_{2}$ & $\mathrm{CaO}$ & $\mathrm{MgO}$ & $\mathrm{Na}_{2} \mathrm{O}$ & $\mathrm{K}_{2} \mathrm{O}$ & $\begin{array}{c}\text { Loss on } \\
\text { Ignition }\end{array}$ \\
\hline 58.41 & 30.40 & 8.44 & 2.75 & 1.3 & 1.53 & 1.0 & 1.98 & 2.4 \\
\hline
\end{tabular}




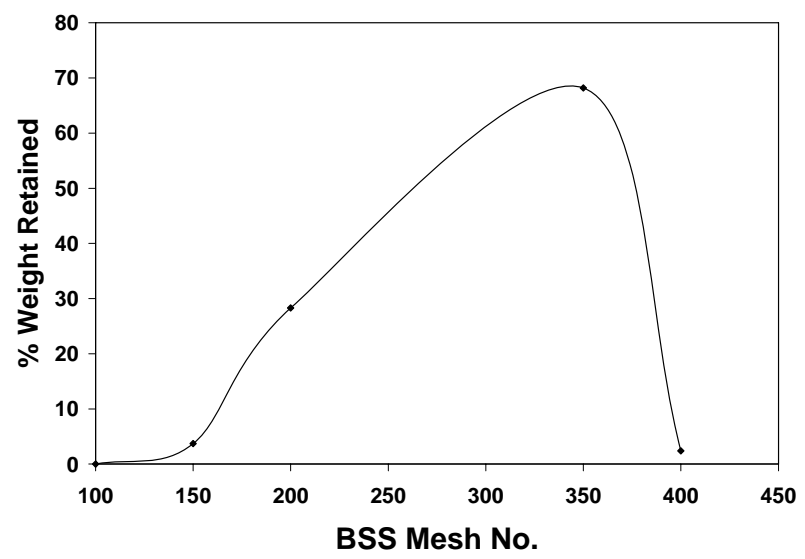

Figure 1. Distribution of as-received fly ash particles on sieving for the period of 15 minutes.

\subsection{High Energy Ball milling}

The reduction in particle size of fly ash from micron level to the nano level was carried out using a high-energy planetary ball mill (Model: Retsch, PM 100, Germany) in a stainless steel chamber using tungsten carbide and zirconia balls of $10 \mathrm{~mm} \Phi$ and 3 $\mathrm{mm} \Phi$ ball sizes respectively. The total duration of milling was 30 hours. The rotation speed of the planet carrier was $250 \mathrm{rpm}$. The ball mill was loaded with ball to powder weight ratio (BPR) of 10:1. Toluene was used as the medium with an anionic surface active agent to avoid agglomeration. The milled sample powder was taken out at a regular interval of every 5 hours of milling. Then this powder was dried by drier and used for further characterization with an X-Ray Diffractometer (Model: 2036E201; Rigaku, Ultima IV, Japan). JADE software was used to investigate the structural changes and phase transformations of powders that occur during mechanical milling. The X-ray diffraction measurements were carried out with the help of a Goniometer model 2036E201 using $\mathrm{Cu} \mathrm{K}_{\alpha}$ radiation $\left(\mathrm{K}_{\alpha}=1.54056 \mathrm{~A}^{0}\right)$ at an accelerating voltage of $40 \mathrm{kV}$ and a current of $20 \mathrm{~mA}$. The samples were scanned in the range from $2^{0}$ to $90^{\circ}, 2-\theta$ and analyzed for crystallite size, peak height, crystallinity and also amount of induced strains in the milled fly ash. Scanning electron microscopy (Model: SEM - Quanta 400, FEI -Netherlands) with EDAX energy dispersive X-ray spectroscopy (EDS) was used in order to evaluate the morphological changes and the elemental analysis of certain phases observed in the nano structured fly ash powder particles.

\subsection{Isothermal Annealing of Nano structured fly ash}

The as-milled fly ash samples were isothermally annealed at a temperature range of 100 and $200{ }^{0} \mathrm{C}$ for 8 hours and from 300 to $800{ }^{\circ} \mathrm{C}$ for 4 hours and cooled in air. An X-Ray Diffractometer (Model: 2036E201; Rigaku, Ultima IV, Japan) with JADE software was used to investigate the structural changes and phase transformations of powders during mechanical milling and subsequent heat treatment. The X-ray diffraction measurements were carried out with the help of a Goniometer model 2036E201 using Cu $\mathrm{K}_{\alpha}$ radiation $\left(\mathrm{K}_{\alpha}=1.54056 \mathrm{~A}^{0}\right)$ at an accelerating voltage of $40 \mathrm{kV}$ and a current of $20 \mathrm{~mA}$. The samples were scanned in the range from $2^{0}$ to $90^{\circ}, 2-\theta$ and analyzed for crystallite size, peak height, crystallinity and also amount of induced strains in the milled fly ash.

\section{Results and Discussion}

\subsection{Crystallite size and Lattice strain}

Figure 2 shows the scanning electron micrograph of the fresh fly ash after heat treatment. From this figure it is evident that majority of the fly ash particles are spherical in nature and precipitator type fly ash. The morphology of fly ash particle is controlled by combustion temperature and cooling rate at the thermal power plant. The X-ray diffraction (XRD) pattern of fly ash in as-received condition is shown in Figure 3, which shows the phases present in the fly ash and are largely Silica $\left(\mathrm{SiO}_{2}\right)$, Alumina $\left(\mathrm{Al}_{2} \mathrm{O}_{3}\right)$, and Mullite $\left(3 \mathrm{Al}_{2} \mathrm{O}_{3} \cdot 2 \mathrm{SiO}_{2}\right)$. 


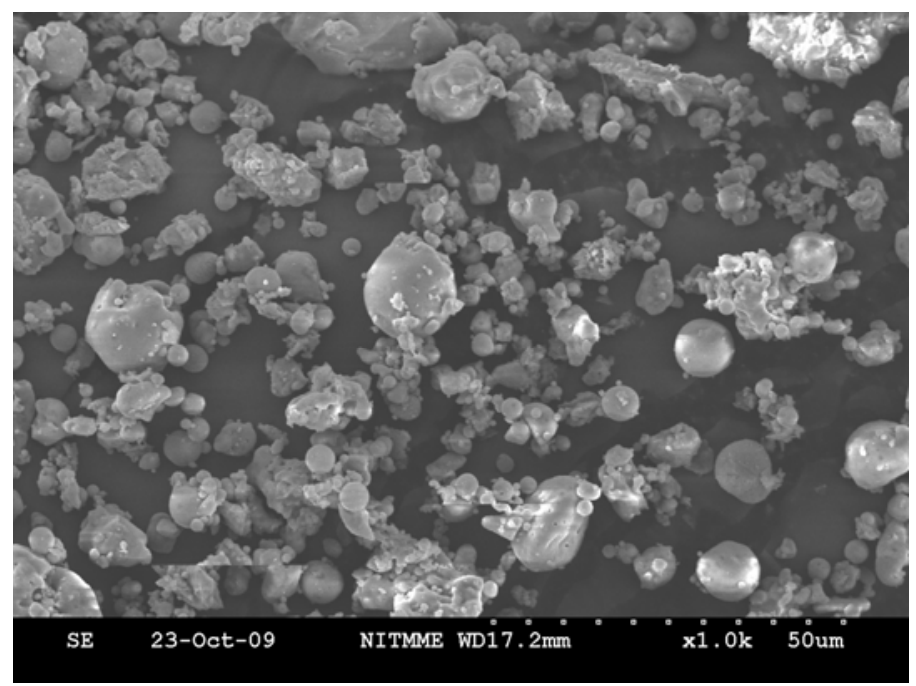

Figure 2. SEM micrograph of fly ash used in the study.

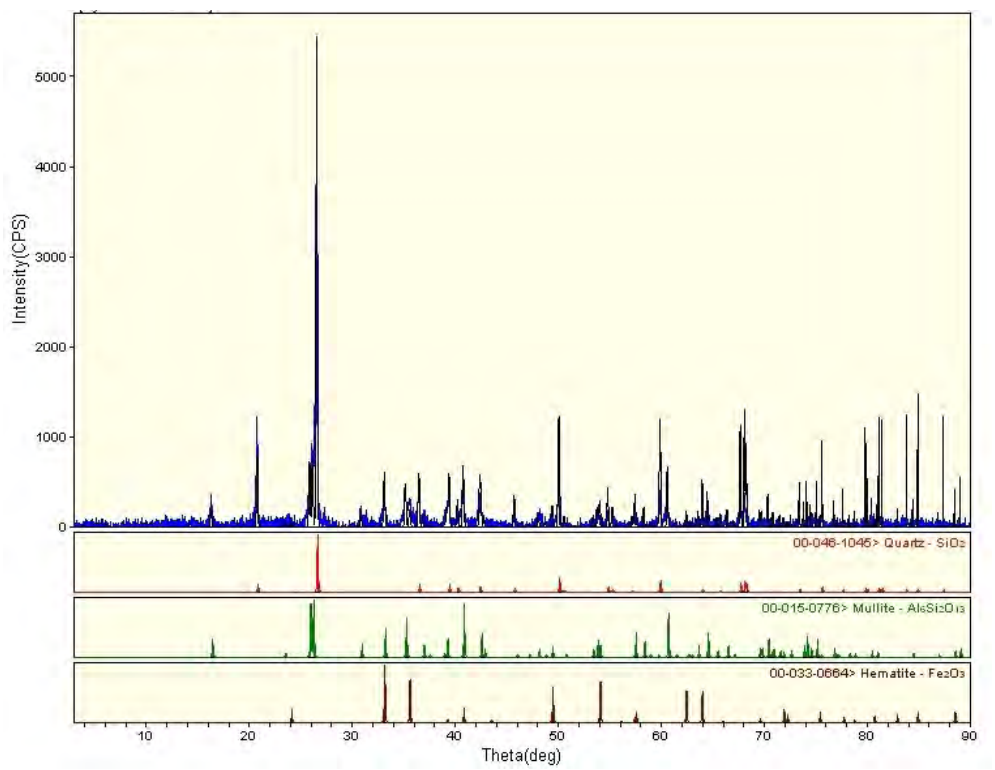

Figure 3. X-ray diffractogram of as-received fly ash.

The average crystallite size was calculated from the full width at half maximum (FWHM) of the X - ray diffraction peak using Scherer's equation (Cullity, 1978).

$$
\mathrm{D}=(\mathrm{k} \lambda) /(\mathrm{B} \cos \theta)
$$

Where $\mathrm{D}$ is the particle diameter, $\lambda$ is the $\mathrm{X}$ - Ray wave length, B is the FWHM of the diffraction peak, $\theta$ is the diffraction angle and $\mathrm{K}$ is the Scherer's constant of the order of unity for usual crystals. The existence of stress in the materials results in lattice distortions of crystals; consequently, the diffraction peaks of the crystals are broadened. The relationship between the half width of the broadened diffraction peaks, $B_{d}$ and the distortion of lattice, $(\Delta d / d)$ was described by Yang et al. (2000). The lattice distortion $(\Delta \mathrm{d} / \mathrm{d})$ can be obtained from the following equation.

$$
(\Delta \mathrm{d} / \mathrm{d})=\mathrm{B}_{\mathrm{d}} /(4 \tan \theta)
$$

Where $B_{d}$, is half width of the broadened diffraction peaks, $\theta$ is half of the diffraction angle.

Figure 4 illustrates the variation in crystallite size and lattice strain of the fly ash with the milling time. A steady decrease in the crystallite size is observed and it was found that the crystallite size get reduced from $92 \mathrm{~nm}$ to $29 \mathrm{~nm}$ for $30 \mathrm{~h}$ milling time. The relative lattice strain is increasing with increasing the duration of milling time. This lattice strain was increased from $0.03 \%$ to $0.36 \%$ for as-received and $30 \mathrm{~h}$ milled fly ash respectively. During ball milling the intense mechanical deformation experienced by the fly ash powder leads to generation of lattice strains, crystal defects and this plus the balance between cold welding and 
fracturing operations among the powder particles is expected to affect the structural changes in the powder. The measurement of crystallite size and lattice strain in the mechanically milled powders is very important since the phase constitution and transformation characteristics appear to be critically depending on them Park et al. (2004).

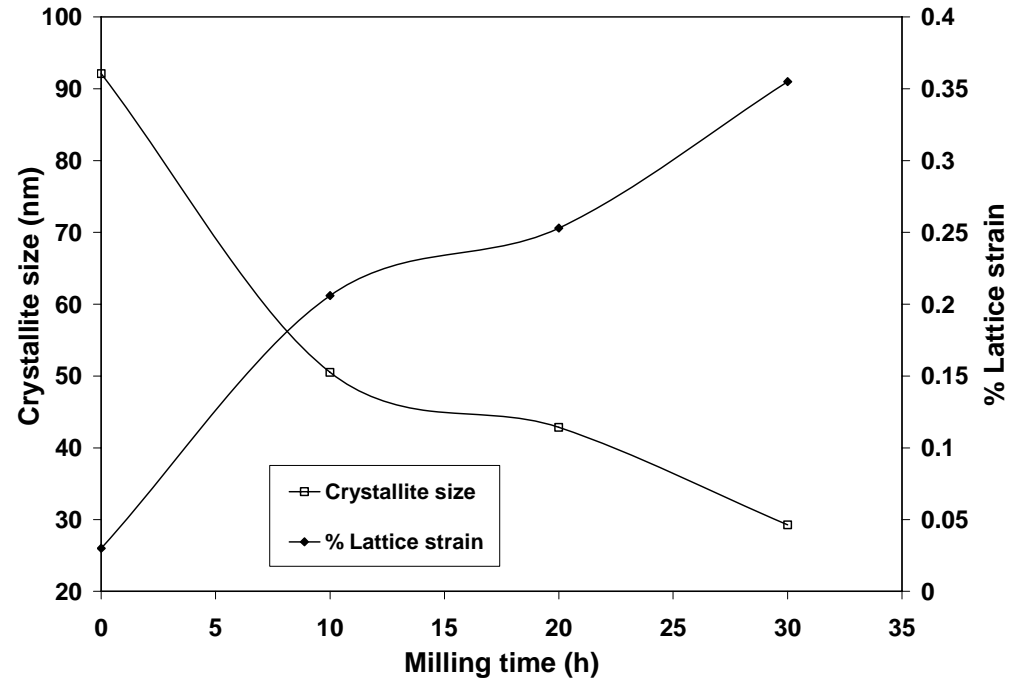

Figure 4. Variation of crystallite size and relative strain as function of milling time.

The size, shape and texture of the fresh as well as nano structured fly ash were studied using Secondary Electron Imaging mode of Scanning electron microscopy (SEM). Figure 5 (a) shows the SEM image of fresh fly ash. The fresh fly ash particles are mostly spherical in shape. The morphology of fresh fly ash particle is controlled by combustion temperature and cooling rate in the thermal power plant. Figure 5 (b) shows the SEM image of 10h ball milled fly ash. Here the spherical structure of fresh fly ash has been destroyed; and in this 10h milling stage the fly ash is in cold welding condition hence the particles appears like enlarged flakes. The large flake shaped particles are further crushed by intense impacts of the balls; hence the decrease in particle size occurs with increasing milling time as shown in Figure 5 (c, d \& e), the SEM images for 20h, 25h and 30h ball milling times respectively. The shape of the particles is irregular and the surface morphology is rough. In order to determine the chemical composition of the nano structured fly ash particles for 30h milled powder, energy dispersion spectrum (EDS) was used. The Figure 6 shows the EDS spectrum of nano structured fly ash. It shows the presence of Al, Si and Oxygen peaks correspond to the Mullite $\left(\mathrm{Al}_{2} \mathrm{O}_{3}\right.$. $\left.\mathrm{SiO}_{2}\right)$ and Silica $\left(\mathrm{SiO}_{2}\right)$ which is present in the fly ash even after micro sized fly ash converted to nano structured fly ash.

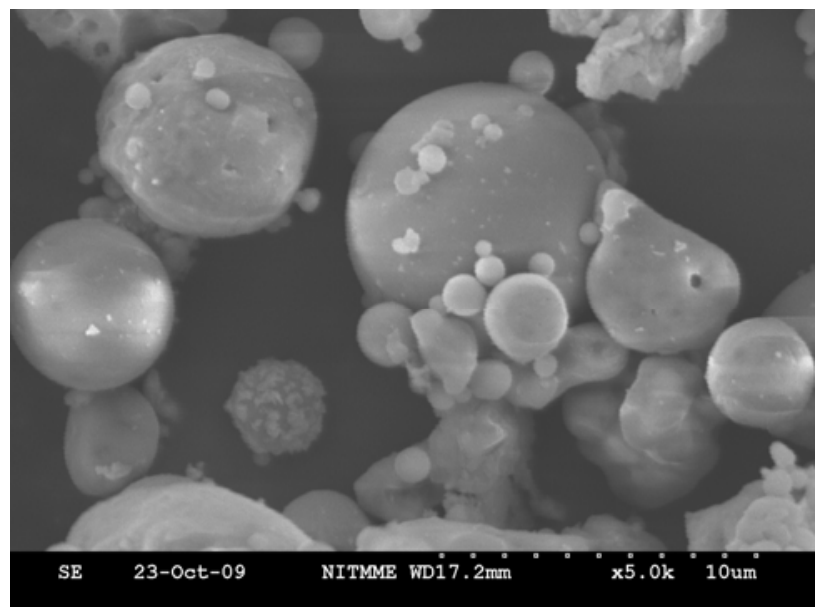

(a)

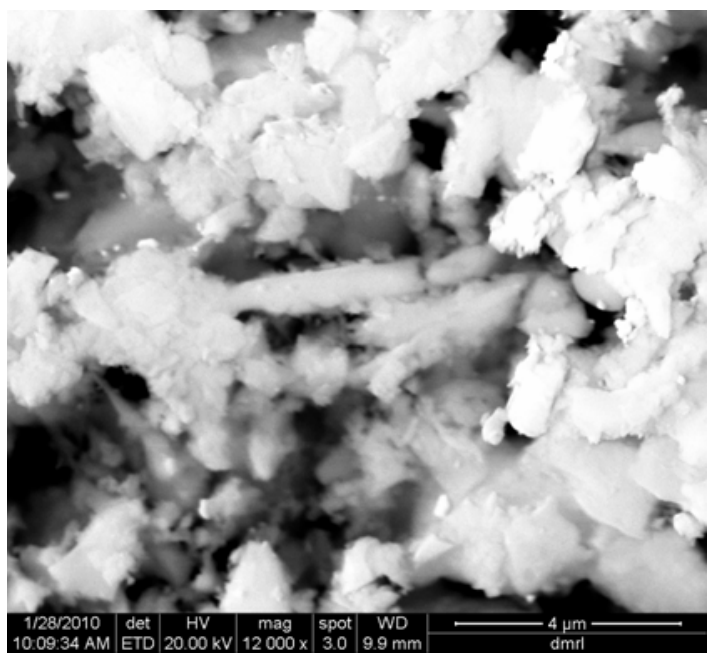

(b) 


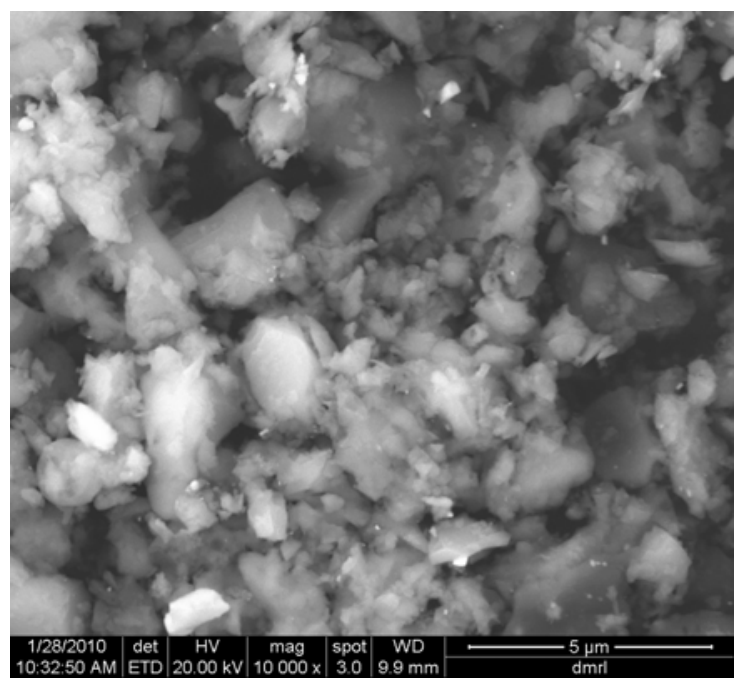

(c)

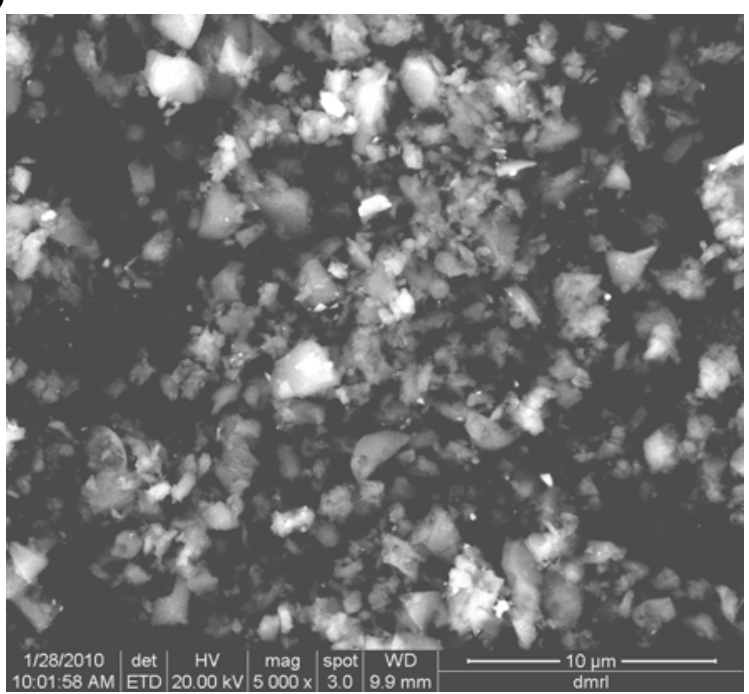

(e)

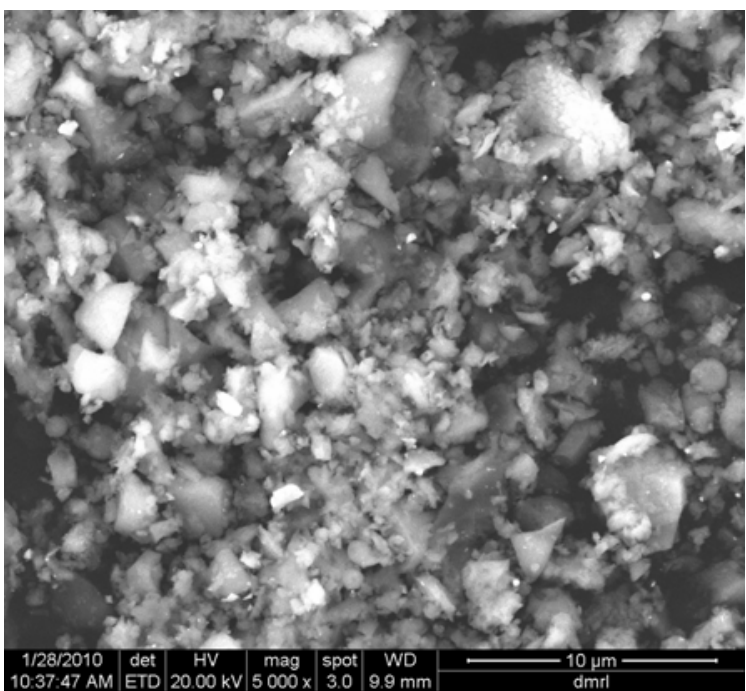

(d)

Figure 5. The scanning Electron microscope photographs of fresh and milled fly ash:

(a) Fresh fly ash (b) Ball milled fly ash for $10 \mathrm{~h}$ (c) Ball milled fly ash for $20 \mathrm{~h}$ (d) Ball milled fly ash for $25 \mathrm{~h}$ (e) Ball milled fly ash for $30 \mathrm{~h}$. 

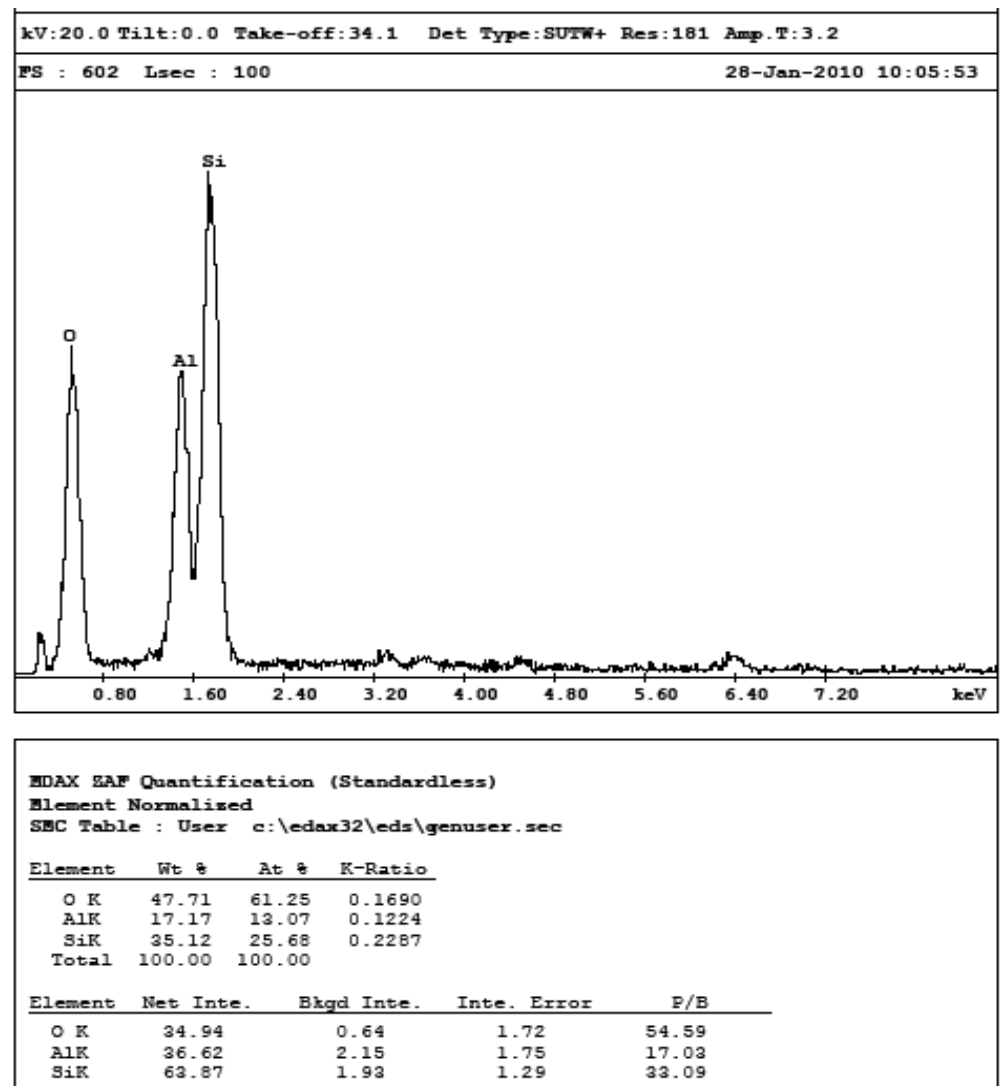

Figure 6. EDX analysis of $30 \mathrm{~h}$ ball milled fly ash.

The X-Ray diffractograms of the fresh as well as ball milled fly ash were shown in Figure 7 (a) and (b). Figure 7 (a) shows the $30 \mathrm{~h}$ milled sample.

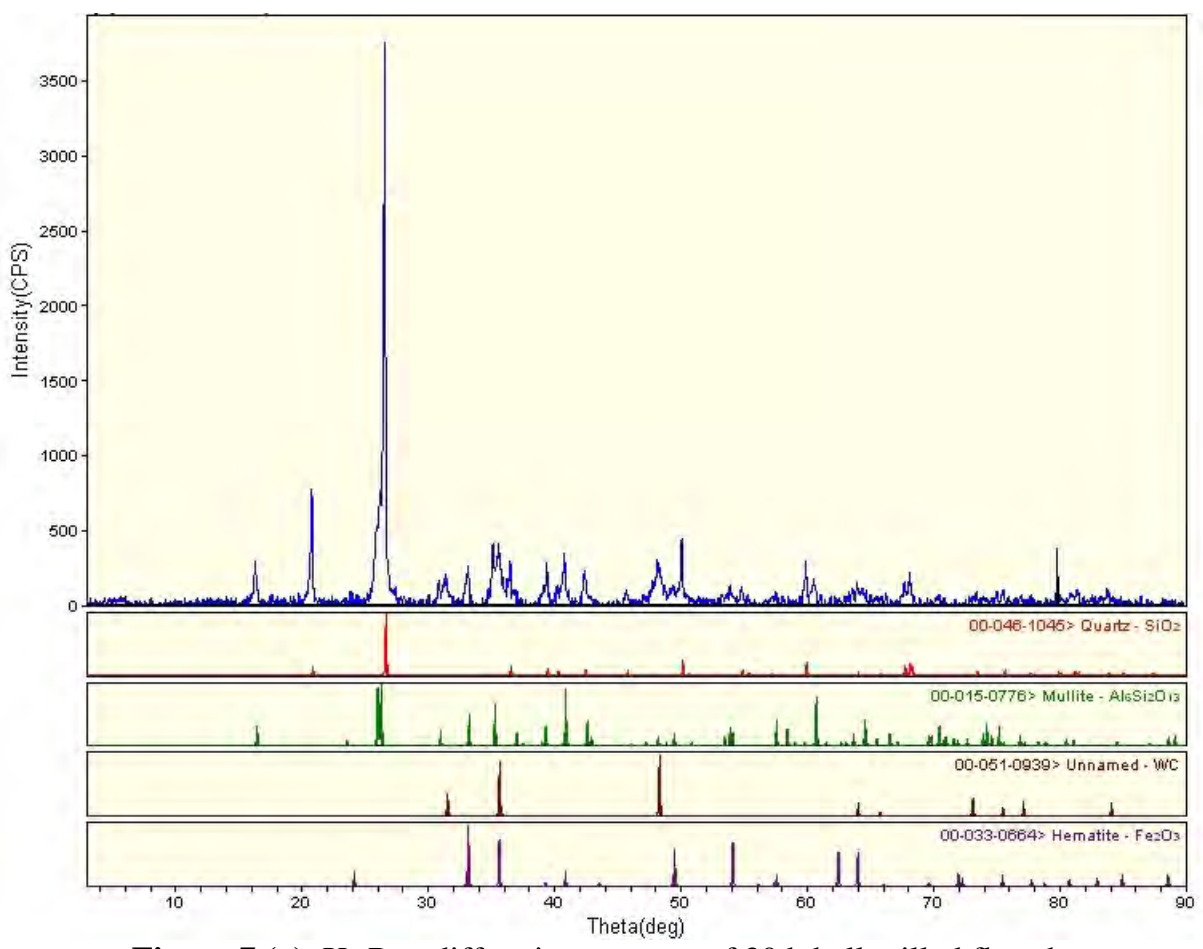

Figure 7 (a). X- Ray diffraction patterns of $30 \mathrm{~h}$ ball milled fly ash.

From this figure, there was a confirmation of small tungsten carbide contamination in the milled fly ash sample. This entry might be from the tungsten carbide balls which were used as milling media during milling. The X-Ray diffractograms of the fresh as well 
as ball milled fly ash were shown in Figure 7 (b). From these figures, it could be clearly observed that the intensity of the sample got reduced and the peak broadening increased as the duration of milling increases; the same was represented for quartz phase in Figure 8. Three major phases were identified for all the milling times; which is Quartz (Silica), Mullite (Alumino Silicate) and Iron Oxide. Quartz phase exhibits strong peaks at $20.82^{0}, 26.60^{\circ}, 36.52^{0}, 50.08^{0}, 59.91^{0}$ and $68.10^{\circ} 2 \theta$ values of (101) plane (d spacing of $4.2631,3.3483,2.4584,1.8198,1.5425$ and $1.3757 \mathrm{~A}^{0}$ ). Mullite phase shows strong peaks at $16.39^{0}, 26.16^{0}, 35.19^{0}$, $41.15^{\circ}$ and $60.61^{\circ} 2 \theta$ values of (210) plane (d spacing of 5.4016, 3.4034, 2.5477, 2.1915 and $1.5264 \mathrm{~A}^{0}$ ). Iron oxide phase shows a peak at $24.19^{0}, 33.16^{0}, 49.74^{0}, 54.84^{0}$ and $64.05^{0} 2 \theta$ values of (104) (d spacing of 3.6764, 2.6993, 1.8313, 1.6727 and $1.4525 \mathrm{~A}^{0}$ ).

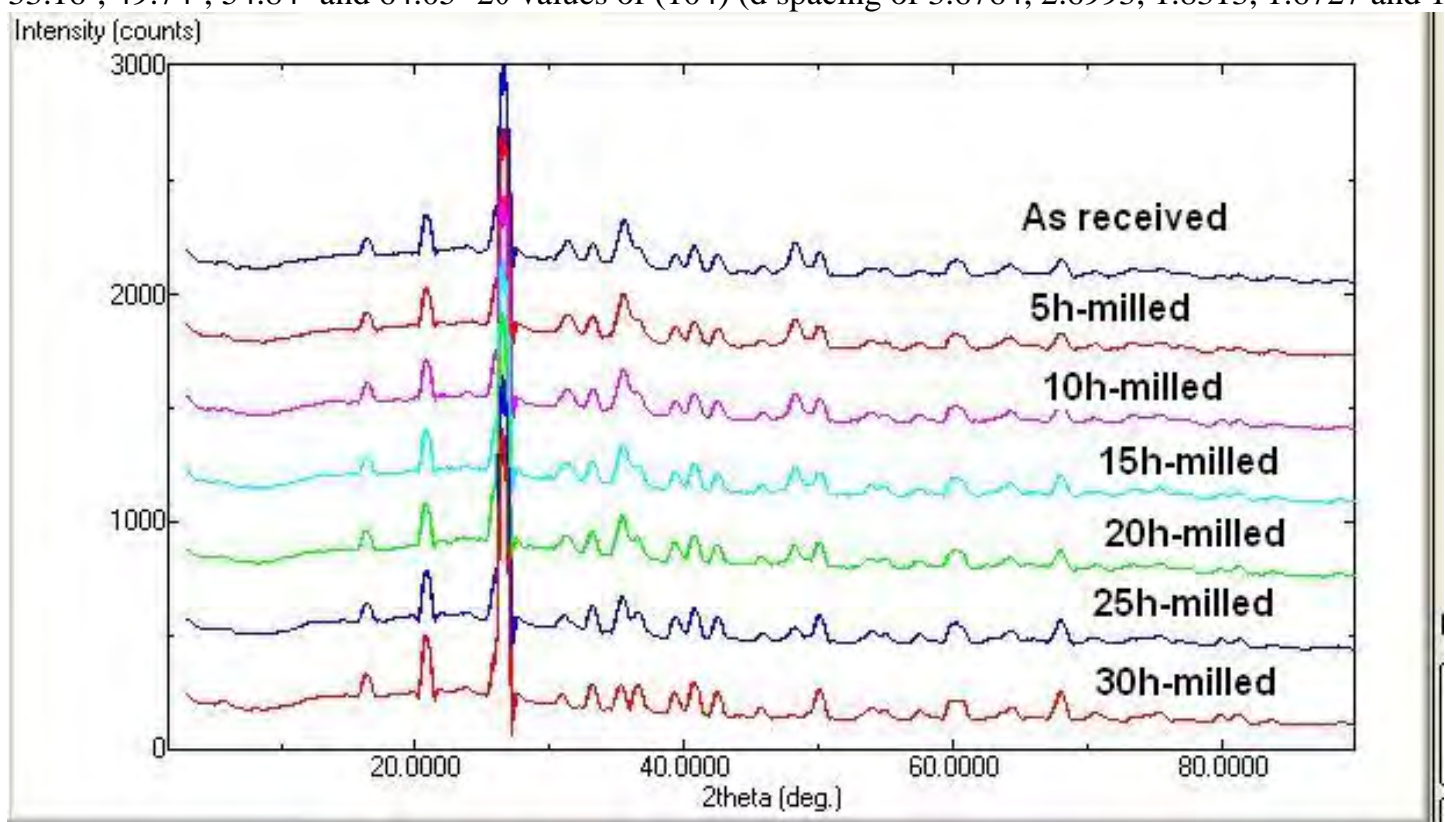

Figure 7 (b). X- Ray diffraction patterns of as-received and ball milled fly ash at different milling times.

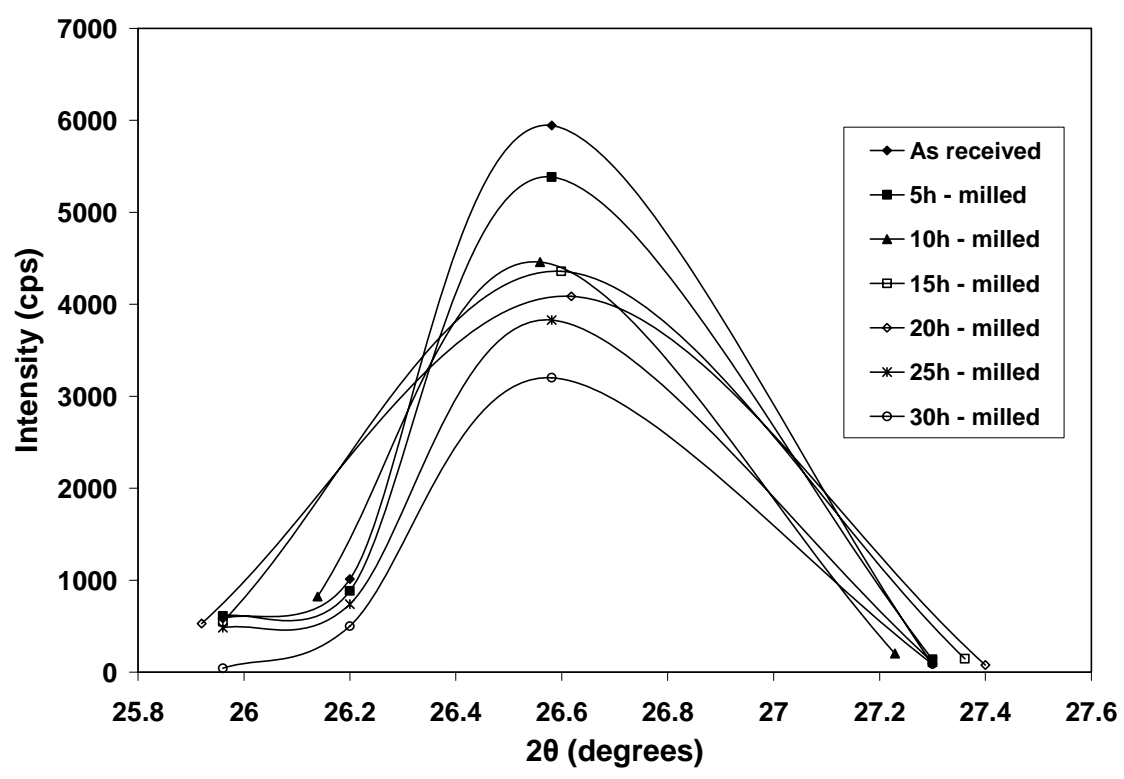

Figure 8. Displacement of $\mathrm{SiO}_{2}$ (101) XRD peaks at different milling times. 


\subsection{Crystallinity}

Crystallinity refers to the degree of structural order in a solid. Crystallinity is usually specified as a percentage of the volume of the material that is crystalline. The decrease in crystallinity of fly ash with ball milling hours is shown in Figure 9. This decrease was observed from $63 \%$ to $38 \%$ for fresh fly ash and 30h ball milled powder respectively. While increasing the milling time decreases the crystallinity of the fly ash, thus increasing the amorphous domains in it. This change is beneficial for the applications such as particulate nano filler in polymeric or metallic matrices. The enhanced amorphous content is very encouraging as it may lead to better compatibility with various metallic and polymeric matrices.

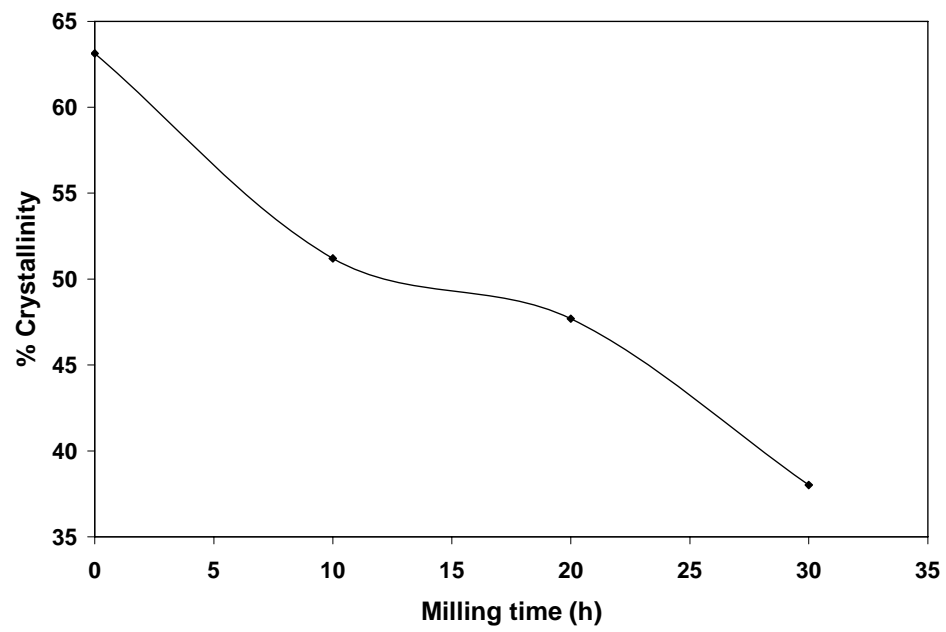

Figure 9: Variation in \% crystallinity with milling time.

\subsection{Structural changes of nano structured fly ash during isothermal annealing}

As discussed in the previous section, 30h mechanical milled-off fly ash powders led to the formation of nano structured fly ash with a crystallite size of $29 \mathrm{~nm}$ and a strain level of $0.09 \%$. This nano structured fly ash generally used as reinforcement for the production of particles reinforced aluminium based nano composites by vortex method. This process involves preheating of the reinforcements at a temperature of $800{ }^{\circ} \mathrm{C}$ for 2 hours and then dispersed into the vortex (created by mechanical stirring) of the molten aluminium alloy melt which will be held at $770{ }^{\circ} \mathrm{C}$ for the period of $15-30$ minutes duration. This entire process may lead to the grain coarsening of nano structure fly ash and may also lead to the composite with micro structured fly ash reinforcements. Therefore significant structural changes can potentially occur upon heating of the as-milled fly ash powder.

Figure 10 and 11 show the variation of crystallite size as a function of annealing time at various temperatures. These figures show the milled nano structured fly ash appeared to have good stability upon annealing either for lower temperatures for longer times or higher temperature with shorter times. The initial grain size of $29 \mathrm{~nm}$ for as-milled sample increases to $30.9 \mathrm{~nm}$ and 31.7 $\mathrm{nm}$ after annealing for $8 \mathrm{~h}$ at 100 and $200{ }^{\circ} \mathrm{C}$ respectively as shown in Figure 10; whereas this trend is slightly higher for higher temperatures. This increase is in the order of $29 \mathrm{~nm}$ to $33.43 \mathrm{~nm}, 35.35 \mathrm{~nm}, 36.53 \mathrm{~nm}, 37.78 \mathrm{~nm}, 40.42 \mathrm{~nm}, 41.93 \mathrm{~nm}$ after annealing for $4 \mathrm{~h}$ at 300, 400, 500, 600, 700 and $800{ }^{\circ} \mathrm{C}$ respectively as shown in Figure 11. Since the ceramic particles have a lower coefficient of thermal expansion (CTE) than metallic alloys (Park et al., 2004; Fei and Wang, 2004; Tjong et al., 2003) and the thermal expansion coefficients of pure aluminium, $\mathrm{SiC}$ and $\mathrm{Al}_{2} \mathrm{O}_{3}$ are reported as $24.7 \mathrm{X} 10^{-6} /{ }^{\circ} \mathrm{C}, 4.8 \mathrm{X} 10^{-6} /{ }^{\circ} \mathrm{C}$ and $7.5 \mathrm{X} 10^{-6}$ / ${ }^{\circ} \mathrm{C}$ respectively (Xu et al., 1994) hence the fly ash which is composed of alumino silicates is expected to be lower CTE than either of $\mathrm{SiC}$ or $\mathrm{Al}_{2} \mathrm{O}_{3}$. Rohatgi et al. (2006) reported the CTE of fly ash cenosphere calculated as $3.3 \times 10^{-6} /{ }^{\circ} \mathrm{C}$ using the rule of mixture. This low CTE of the fly ash would results the retaining of nano structured size even after annealing at either $200{ }^{\circ} \mathrm{C}$ for 8 h or $800{ }^{\circ} \mathrm{C}$ for $4 \mathrm{~h}$.

Figure 12 (a-c) shows the morphology of Fly Ash particles after annealing at $200{ }^{0} \mathrm{C}$ for 8 hrs, $400{ }^{0} \mathrm{C}$ and $800{ }^{0} \mathrm{C}$ for 4 hrs respectively. It can be seen that the nano particles are slightly enlarged its size due to higher annealing temperatures. In order to determine the chemical composition of the nano particles, energy dispersion spectrum (EDS) was used. It is evident that $\mathrm{Si}, \mathrm{Al}$ and O peaks correspond to composition of nano particles. 


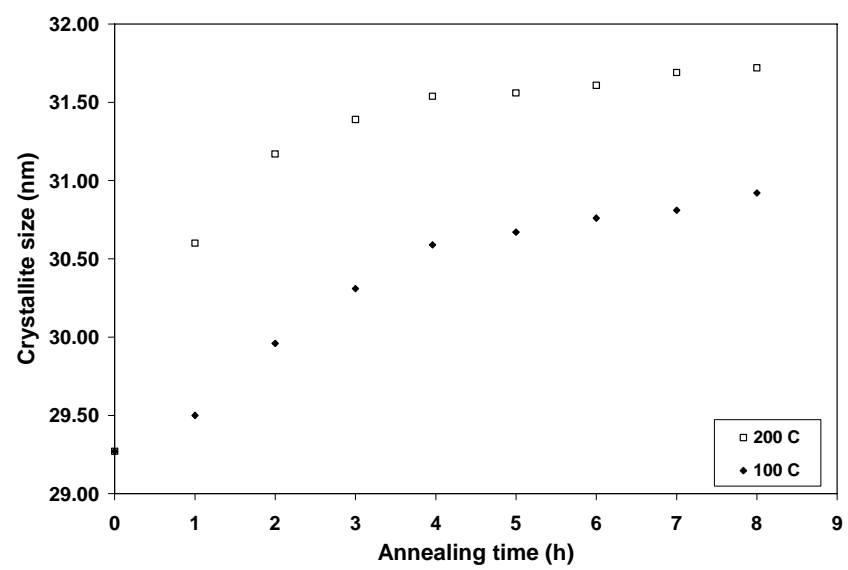

Figure 10. Variation of $30 \mathrm{~h}$ - milled fly ash crystallite size as function of annealing time for lower range of annealing temperature

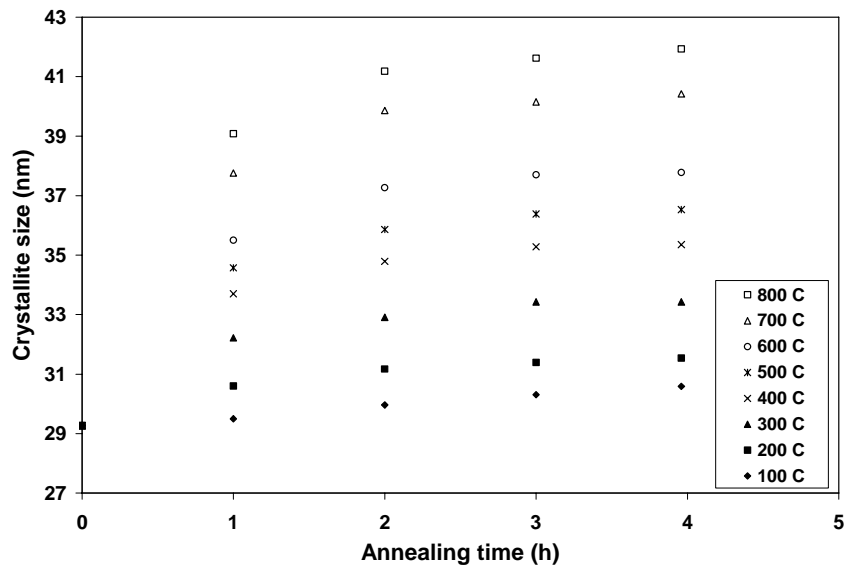

Figure 11. Variation of $30 \mathrm{~h}$ - milled fly ash crystallite size as function of annealing time for higher range of annealing temperature 

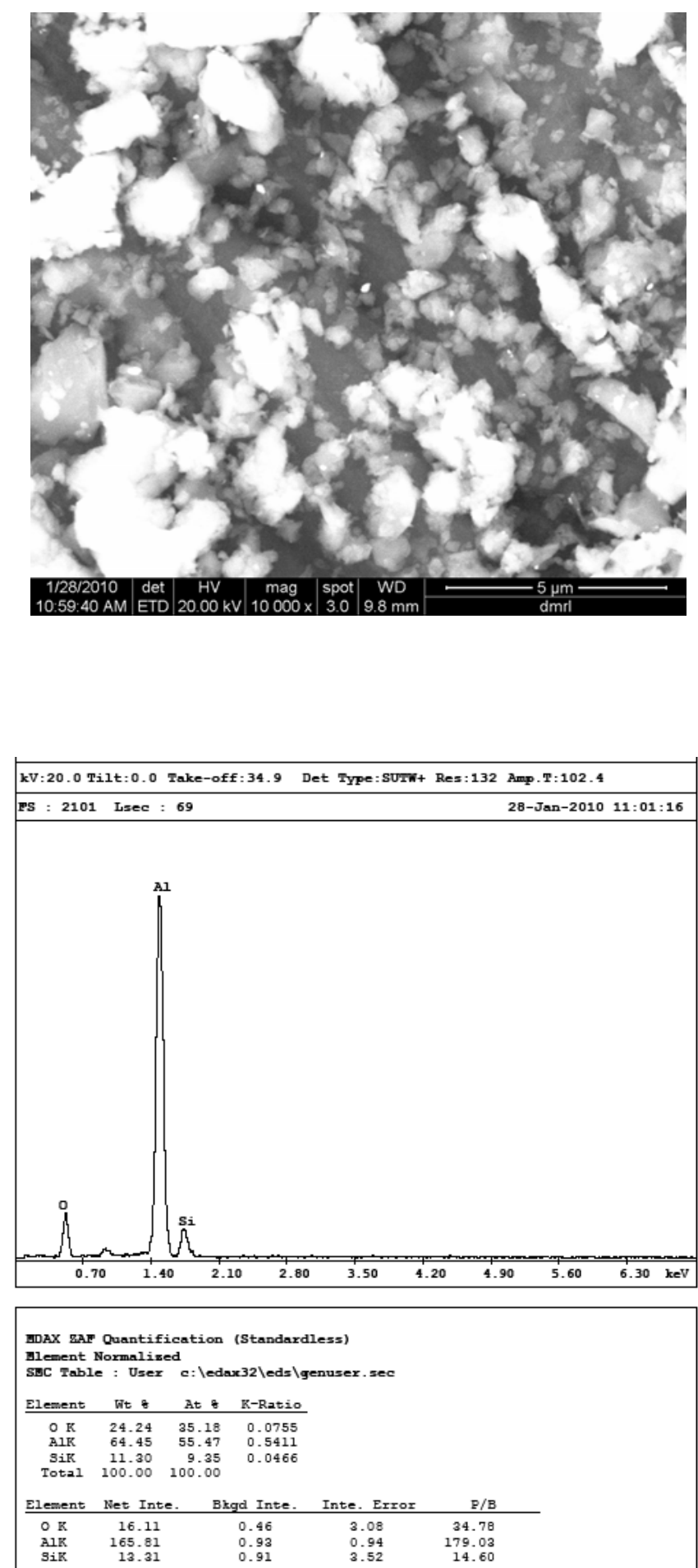

(a) $200{ }^{\circ} \mathrm{C}-8 \mathrm{hrs}$ 

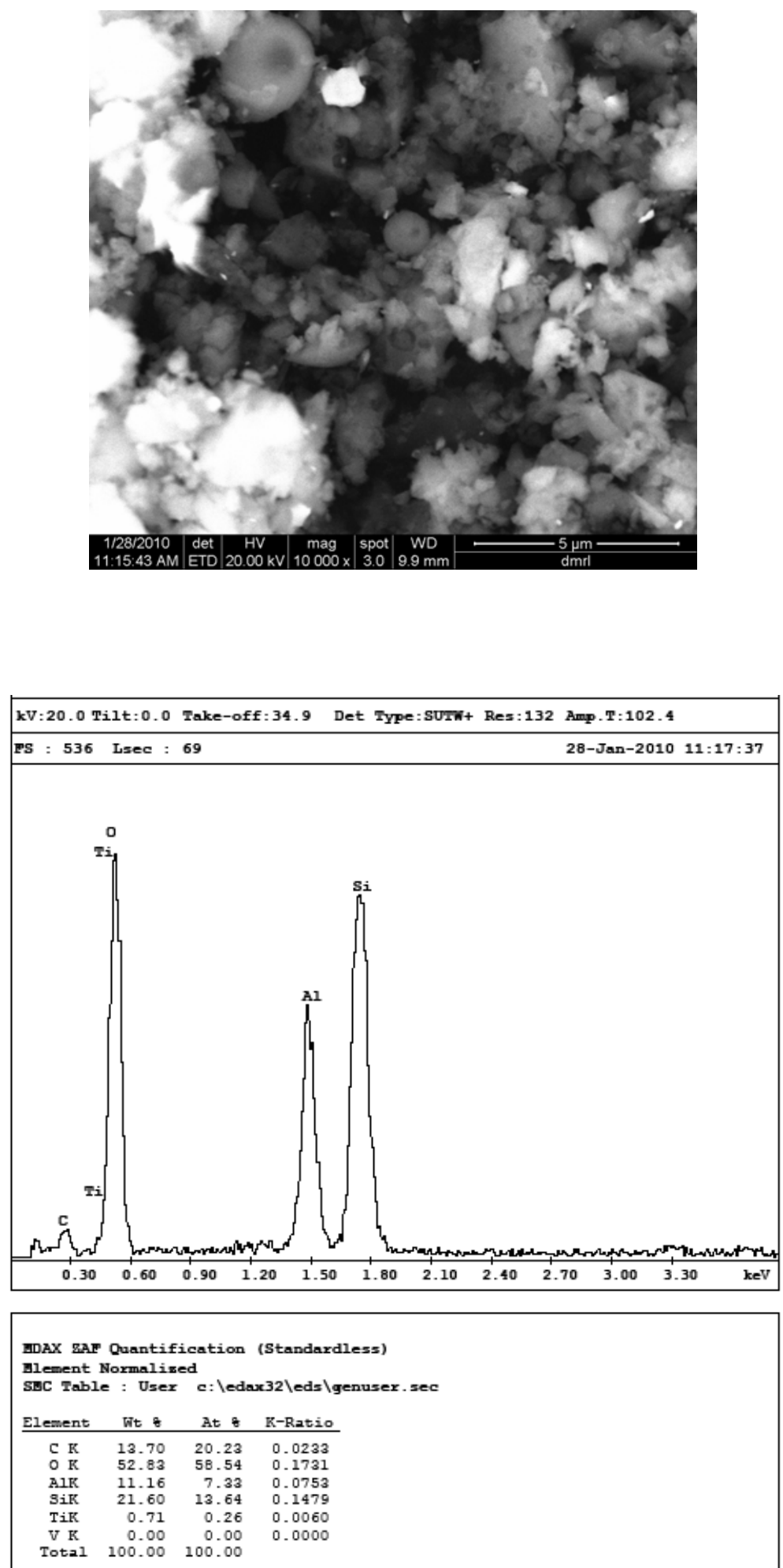

(b) $400{ }^{\circ} \mathrm{C}-4 \mathrm{hrs}$ 

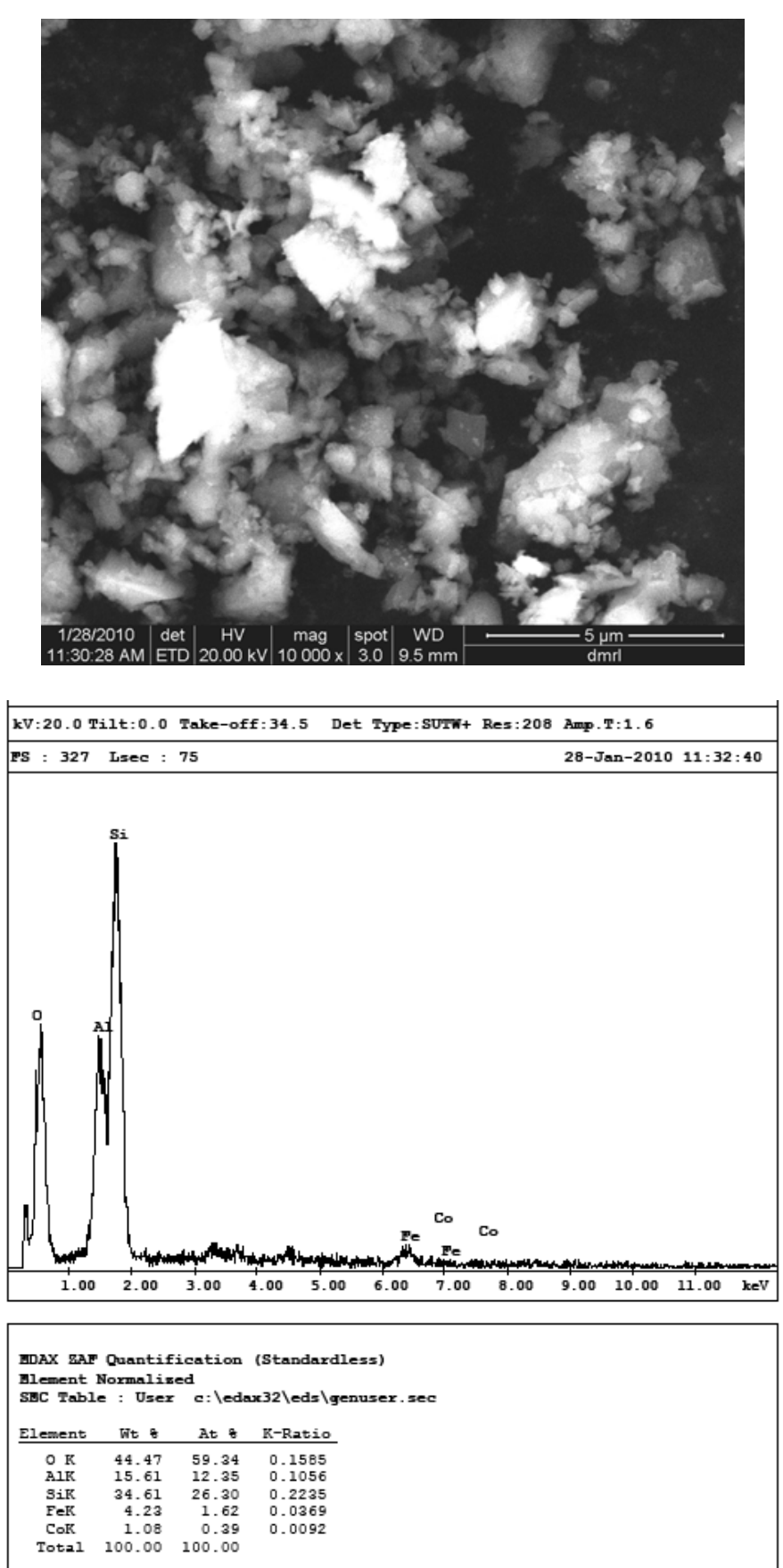

(c) $800{ }^{\circ} \mathrm{C}-4 \mathrm{hrs}$

Figure 12. The scanning Electron microscope photographs with EDS analysis of 30h milled and annealed for 4 hrs at different annealing temperatures: (a) $200{ }^{\circ} \mathrm{C}-8 \mathrm{hrs}$ (b) $400{ }^{\circ} \mathrm{C}-4$ hrs (c) $800{ }^{\circ} \mathrm{C}-4 \mathrm{hrs}$

Figure 13 (a \& b) shows the 30h milled nano structured fly ash powders annealed for various annealing times at different annealing temperatures of 100 and $200{ }^{\circ} \mathrm{C}$ for $8 \mathrm{~h}$ and $300-800{ }^{\circ} \mathrm{C}$ for 4 hours to asses the recovery of lattice strain in the milled powder. If the temperature is high, the associated higher diffusivity (higher atomic mobility) leads to processes resulting in recovery and recryastallization; on the other hand, if the temperature is low then strain recovery would be less (Koch, 1993). So that the initial strain of $0.355 \%$ for as-milled sample decreases to $0.151 \%$ and $0.135 \%$ after annealing for $8 \mathrm{~h}$ at 100 and $200{ }^{\circ} \mathrm{C}$ respectively as shown in Figure 13 (a); whereas this trend is slightly higher for higher temperatures. This decrease is in the order of $0.355 \%$ to $0.21 \%, 0.183 \%, 0.151 \%, 0.146 \%, 0.143 \%$ and $0.14 \%$ after annealing for $4 \mathrm{~h}$ at $300,400,500,600,700$ and $800{ }^{\circ} \mathrm{C}$ respectively as shown in Figure 13 (b). For the longer annealing times and higher annealing temperature show the way to the very low strain levels in the milled powder. 


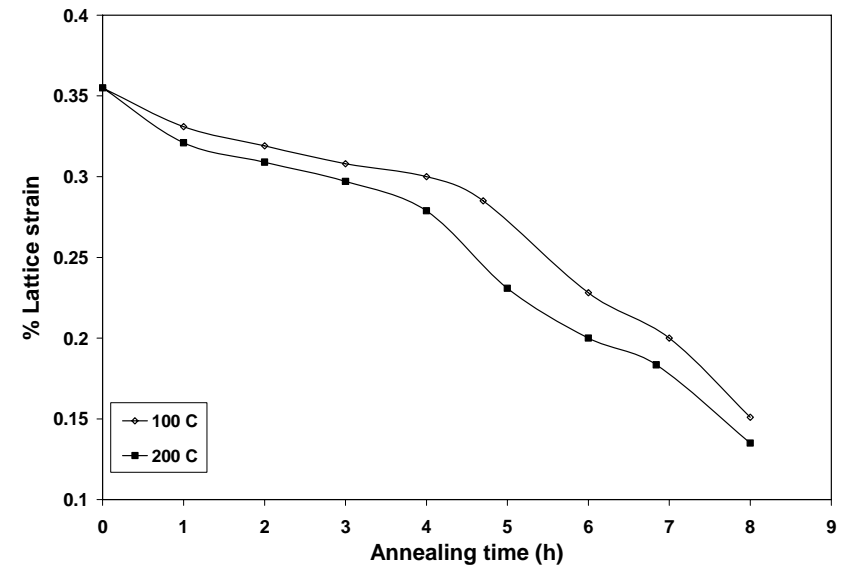

(a)

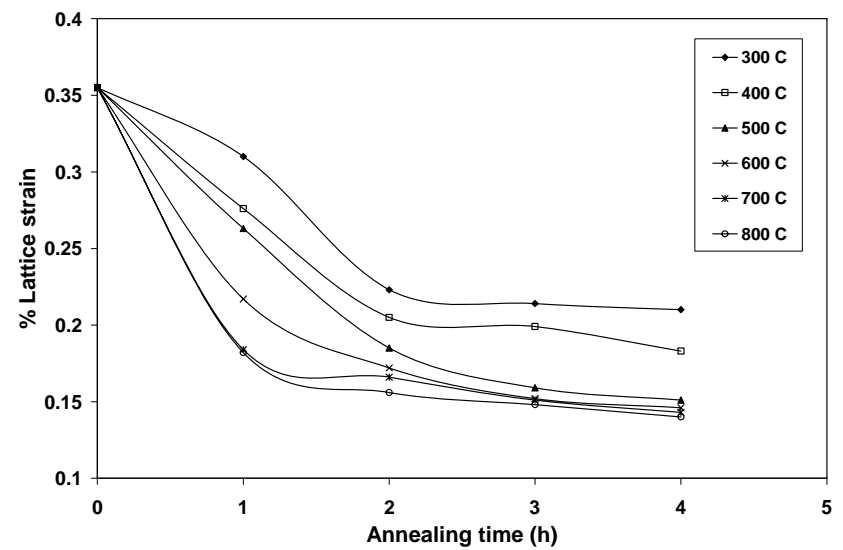

(b)

Figure 13. Internal residual strain of $30 \mathrm{~h}$ - milled nano structured fly ash as function of annealing temperature for various annealing times (a) Low range of annealing temperature (b) High range annealing temperature.

Figure 14 shows the XRD patterns of the $30 \mathrm{~h}$ - milled fly ash after annealing at different temperatures for $4 \mathrm{~h}$.

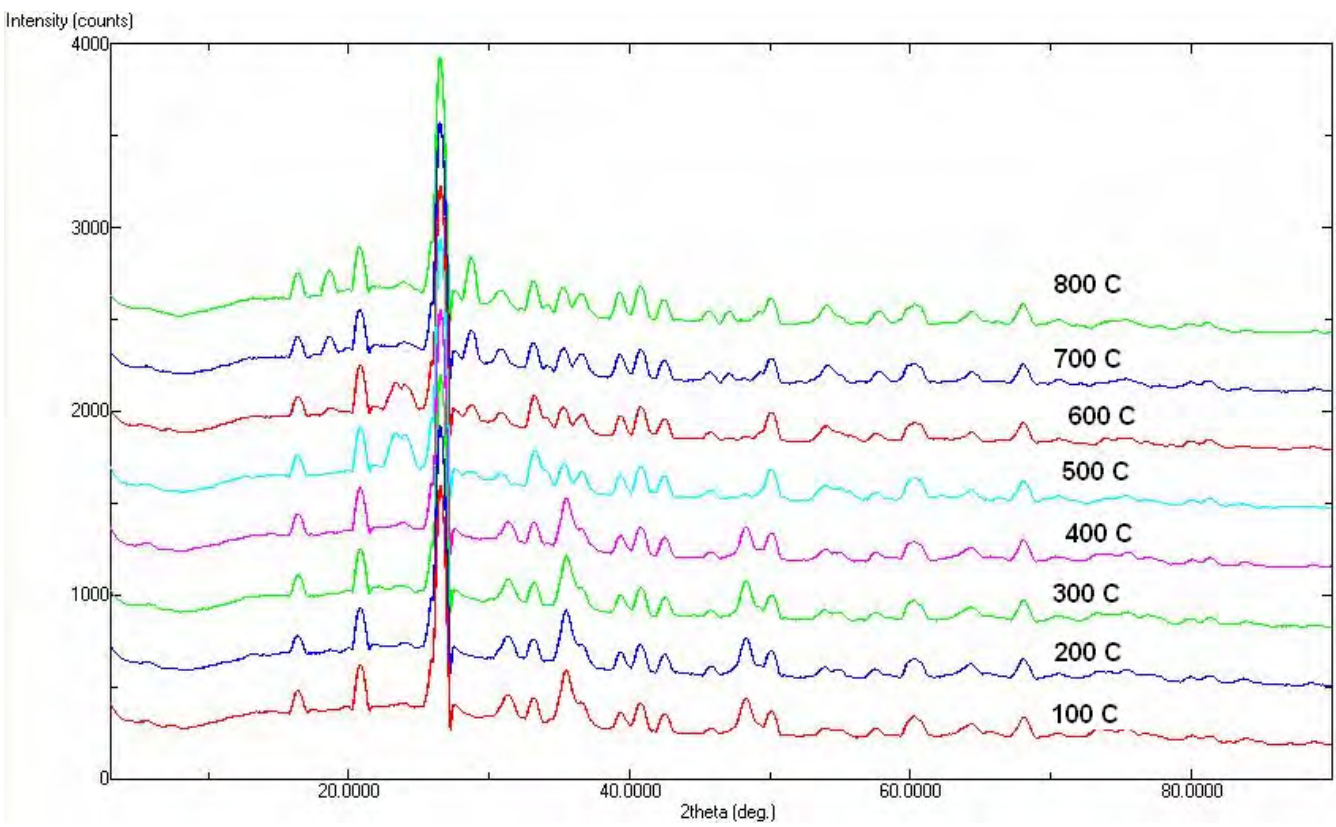

Figure 14: XRD patterns of $30 \mathrm{~h}$ milled Fly ash powder particles after annealing for $4 \mathrm{~h}$ at various temperatures Three major phases were identified for all the annealing temperatures; which are Quartz (Silica), Mullite (Alumino Silicate) and Iron Oxide and also small amount of Tungsten Carbide (WC) was present as contamination. At $500{ }^{\circ} \mathrm{C}$ tungsten oxide $\left(\mathrm{WO}_{3}\right)$ 
appeared in the fly ash particles; which might be due to the reaction between Tungsten carbide (WC) and oxygen from the oxides of either Silica, Mullite or from Iron oxide. At $700{ }^{\circ} \mathrm{C} \mathrm{WO}_{3}$ was converted to $\mathrm{WO}_{4}$.

\section{Conclusions}

The size reduction of fly ash from micrometer level to nano meter levels has been achieved by high energy ball milling for the period of $30 \mathrm{hrs}$. The percentage of crystallinity reduces from $63 \%$ to $38 \%$. The fly ash becomes more amorphous and the crystallite size reduces drastically. The lattice strain was increased with increasing the milling time. $\mathrm{The}^{\mathrm{SiO}} \mathrm{P}_{2}$ phase is the maximum sufferer during milling; hence with increasing the milling time $\mathrm{SiO}_{2}$ peaks shifts slightly to the lower angels and also broadening of the diffraction pattern occurs. Small crystallite size enhancement with good amount of residual strain recovery was observed during the isothermal annealing process. By and large, nano structure still exists in the 30h ball milled fly ash even after the isothermal annealing. Currently, the author is utilizing this nano structured fly ash for synthesis of Aluminium- fly Ash metal matrix nano composites (MMNC). The work is on progress and the results will be presented in the next publication.

\section{Acknowledgements}

The authors thank the AICTE-CAYT ((File No: 1-51 /FD/CA/ (19) 2006-2007), New Delhi and UGC-MRP (File No: 34 396/2008 (SR)), New Delhi, India for their financial support, Center for Nano Technology and Department of Metallurgical Engineering, Andhra University College of Engineering, Visakhapatnam, India for providing necessary support in conducting the experiments and also Dr. Bhav Singh, Scientist-D, DMRL- Hyderabad and NIT- Tirchy, India for their support in SEM-EDX studies.

\section{References}

Akio, K., Atsushi, O., Toshiro, K., Hiroyuki, T., 1999, Journal of Jpn. Inst. Light Met, Vol. 49, pp.149-154.

Ansary Yar, A., Montazerian, M., Habdizadeh, H., Baharvandi, H.R., 2009, Microstructure and mechanical properties of aluminium alloy matrix composite reinforced with nano- particle MgO, Journal of Alloys and Compounds, Vol. 484, pp. 400404.

Baraton M.I., 2003, Synthesis, functionalization and surface treatment of Nano particles, American Scientific publication, USA. Bhushan, B, 2004, Springer handbook of nanotechnology Springer - Verlag, Germany.

Boylan, K., Ostrander, D., Erb, U., Palumbo, G., Aust, K.T., 1991, An in-situ tem study of the thermal stability of nanocrystalline Ni, Scripta Materialia, Vol. 25, No. 12, pp. 2711-2716.

Carl C Koch, 2006, Nano structured materials processing, properties and applications, William Andrew Inc.- NY, USA.

Chen, X.F., Baburai, E.G.. Froes, F.H., Vassel, A., 1997, Proc. Adv. Part. Mater. Processes, pp.185-192.

Cullity B D., 1978, Elements of X-ray diffraction, $2^{\text {nd }}$ edition, Addison- Wesley, California USA.

Daoud. A, Abou El-Khair. M. T, Shenouda. A. Y, Mohammed. E and Rohatgi. P.K, 2009, Microstructure, tensile properties and electrochemical behaviour of $\mathrm{Pb}$ alloy-45 vol\% fly ash microballoon composites, Materials Science and Engineering- $A$, Vol. 526, pp. 225-234.

De Castro, C.L., Mitchell, B.S., 2005, Materials Science and Engineering- A, Vol. 396, pp. 124-128.

Fei, W.D., Wang L.D.,2004, Thermal expansion behaviour and thermal mismatch stress of aluminium matrix composite reinforced by $\beta$-eucryptite particle and aluminium borate whisker, Materials Chemistry and Physics, Vol. 85, No. 2-3, pp. 450457.

Groza, J.R., 1999, Sintering of nanocrystalline powders, Int J Powder Metall. Vol. 35, No. 7, pp. 59-66.

Guozhong Cao, 2004, Nanostructures and Nano materials- Synthesis, properties and Applications, Imperial College Press, USA.

Habibnejad-Korayem, M., Mahumudi, R., Poole, W.J., 2009, Enhanced properties of Mg-based composites reinforced with $\mathrm{Al}_{2} \mathrm{O}_{3}$ nano-particles, Materials Science and Engineering-A, Vol. 519, pp.198-203.

http://www.tifac.org.in/news/flyindia.htm. Assessed 03 September, 2010.

Habibnejad-Korayem, M., Mahumudi, R., Ghasemi, H.M., Poole, W.J., 2010, Tribological behavior of pure Mg and AZ31 magnesium alloy strengthened by $\mathrm{Al}_{2} \mathrm{O}_{3}$ nano particles, Wear, Vol. 268, pp. 405-412.

Kumar, P.R.S., Kumaran, S., Srinivasa Rao, T., Siva Prasad, K., 2009, Microstructure and mechanical properties of fly ash particles reinforced AA6061 composites produced by press and extrusion, Transactions of The Indian Institute of Metals, Vol. 62, No. 6, pp. 559-566.

Kohlar, M, Fritzsche, W., 2004, Nano Technology - An introduction to Nano structuring Techniques, Wiley - VCH- Verlag, Germany.

Koch, C.C., 1993, The synthesis and structure of nanocrystalline materials produced by mechanical attrition: a review, Nanostructured Materials, Vol. 2, pp. 109-129.

Kumar, V., Abraham Zacharia, K., Sharma, P., 2007, Fly Ash Utilization: Indian Scenario \& Case Studies.

Lan J., Yang Y., Li X., 2003, Microstructure and microhardness of SiC nano particles reinforced magnesium composites fabricated by ultrasonic method, Materials Science and Engineering- A, Vol. 386, pp. 284-290. 
Mondal, D.P., Das, S., Nidhi Jha, 2009, Dry sliding wear behaviour of aluminium syntactic foam, Journal of Materials and Design, Vol. 30, pp. 2563-2568.

Matsunaga, T., Kim, J. K., Hardcastle, S., Rohatgi, P.K., 2002, Crystallinity and selected properties of fly ash particles, Materials Science and Engineering- A, Vol. 325, pp. 333-343.

Mazahery, A., Habdizadeh, H., Baharvandi, H.R., 2009, Development of high -performance A356/nano $\mathrm{Al}_{2} \mathrm{O}_{3}$ composites, Materials Science and Engineering-A, Vol. 518, pp. 61-64.

Mussert K.M., Vellinga W.P., Bakker A., Zwaag V., 2002, A Nano-indentation Study on the Mechanical Behaviour of the Matrix material in an AA6061-Al2O3 MMC, J. Mat. Sci., Vol. 37, No. 4, pp. 789-794.

Park, C. S., Kim C. H., Kim M. H., and Lee, C., 2004, The effect of particle size and volume fraction of the reinforced phases on the linear thermal expansions in the Al-Si-SiCp system, Materials Chemistry and physics, Vol. 88, No.1, pp. 46-52.

Ramachandra, M., Radhakrishna, K., 2007, Effect of reinforcement of fly ash on sliding wear, slurry erosive wear and corrosive behaviour of aluminium matrix composite, Wear, Vol. 262, pp. 1450-1462.

Rohatgi, P.K., Gupta, N., and Simon Alaraj., 2006, Thermal expansion of Al-Fly ash cenospehere composites synthesized by pressure infiltration technique, Journal of Composite Materials, Vol. 40, No. 13 pp.1163-1174.

Shaw, L., Luo, H., Villegas, J., Miracle, D., 2003, Acta Materialia, Vol. 51, pp. 2647-2663.

Sudarshan, S.M.K., 2008, Synthesis of fly ash particles reinforced A356 Al composites and their characterization, Materials Science and Engineering- A, Vol. 480, pp. 117-124.

Suryanarayana, C., 2001, Mechanical alloying and milling, Progress in Materials Science, Vol. 46, pp.1-184.

Tjong, S.C, Tam,K.F and Wu S.Q., 2003, Thermal cycling characteristics of in-situ Al-based composites prepared by reactive hot pressing, Composite Science and Technology, Vol. 63, pp. 89-97.

Utriga Filho, S.L., Rodriguez, R., Eartman, J.C., Lavernia, E.J., 2003, Mater Sci. Forum, Vol. 416-418, pp. 213-218.

Uju W.A., Oguocha I.N.A., 2009. Thermal cycling behaviour of stir cast Al-Mg alloy reinforced with fly ash, Materials Science and Engineering- A, Vol. 526, pp. 100-105.

Xu, Z.R., Chawala, K. K., Mitra, R. and Fine M. E., 1994, Effect of particle size on the thermal expansion of TiC/Al XD ${ }^{\mathrm{TM}}$ composites, Scripta Materiallia, Vol. 31, No. 11, pp.1525-1530.

Yang Q., Zhao L., Xiao H. and Zhao N., 2000, Analysis of Intrinsic Stress In Diamond Films By X-Ray Diffraction”, International Centre for Diffraction Data, Advances in X-ray Analysis,Vol.43, pp.151-156.

Yang Y., Lan J., Li X., 2004, Study on bulk aluminium matrix nano- composite fabricated by ultrasonic dispersion on nano sized SiC particles in molten aluminium alloy, Materials Science and Engineering- A, Vol. 380, pp. 378-383.

Zhou, F., Lee, J., Lavernia, E.J., 2001, Grain growth kinetics of a mechanically milled nanocrystalline Al, Scripta Mater, Vol. 44, pp. 2013-2017.

\section{Biographical notes}

Dr. Babu Rao Jinugu, working as Associate Professor in the Dept. of Metallurgical Engineering, AU College of Engineering, Andhra University, Visakhapatnam since May 2000. He completed his B. Tech and M. Tech in Metallurgical Engineering from NIT Warangal and Ph. D from Andhra University, Visakhapatnam. Prior to join in this University, he worked as Assistant Manager (QA \& TD), R\&D division of RINL, Visakhapatnam Steel Plant, Visakhapatnam since Sept'1995April 2000 and also worked as Scientist in C-MET Laboratories, Dept of Electronics, Hyderabad for a period of two months (August - September 1995). He is the Life member for The Indian Institute of Metals (IIM) - Kolkata, Life Member for Tribology Society of India (TSI) and Life member for The Institution of Engineers (IEI). At present he is holding the positions of Joint Secretary - IIM Visakhapatnam Chapter, Chairman - IIM Visakhapatnam Students Chapter and Member- Editorial Board of IIM News Magazine. Currently working for UGC, New Delhi sponsored Major Research Project (File No: 34 -396/2008 (SR) on "Synthesis and Characterization of Al-Fly Ash Nano Composites" and also working for one AICTE, New Delhi sponsored research project (File No: 1-51/FD/CA/ (19)2006-2007) on "Studies on cold workability limits of Aluminium and its alloys". He was chosen by AICTE-New Delhi as "Career Award for Young Teacher" in the year 2007. He has visited Beijing, China and Singapore in the year 2008 for participation and presenting the papers at various international conferences. At present, a total of 53 Research Papers were published at various national and International journals/ conferences. His current areas of research are Nano Composite Materials and Metal Forming.

P Narayanaswami is a student of M Tech (nano Technology) in the Dept of Metallurgical Engineering, AU College of Engineering, Andhra University, Visakhapatnam, India.

Dr. K Siva Prasad working as Assistant Professor in the Dept of Metallurgical and Materials Engineering, National Institute of Technology, Trichy, Tamil Nadu, India. He obtained his M Tech and Ph D from the Indian Institute of Technology, Madras, Chennai, India. He is author of more than 50 national and international Journals.

Received July 2010

Accepted August 2010

Final acceptance in revised form August 2010 